\title{
Relações de incerteza e exclusão: é possível pensar em estratégias para a educação em tempos de pandemia?
}

\author{
Relations of uncertainty and exclusion: is it possible to think about \\ strategies for education in times of a pandemic?
}

\begin{abstract}
Relaciones de incertidumbre y exclusión: ¿Es posible pensar en estrategias para la educación en tiempos de pandemia?
\end{abstract}

Maria de Fátima Barbosa Abdalla I

https://orcid.org/0000-000I-8290-959X

Resumo: A partir de um olhar psicossocial este texto objetiva discutir a Educação em tempos de pandemia. Parte-se do pressuposto de que é preciso elucidar epistemologicamente algumas noções teóricas, que entretecem relações de incerteza e de exclusão, presentes nas práticas cotidianas, para que se possa compreender os efeitos da pandemia no cenário educacional e refletir sobre estratégias de ação e de superação. Fundamenta-se em Bourdieu (1997, 1998, 2002, 2015), Certeau (1998), Morin (2000, 2003), entre outros, para oferecer subsídios teóricos no sentido de refletir sobre o cotidiano educacional, suas regras e estratégias e seus processos de exclusão. Espera-se, assim, identificar os desafios postos pelas incertezas e pelo flagelo neoliberal desse tempo de pandemia, e de interrogar as condições de possibilidades e formas de resistência, em especial, da escola, na garantia dos direitos sociais e de uma educação mais justa e inclusiva.

Palavras-chave: Educação. Relações de incerteza e exclusão. Estratégias de ação e superação.

\begin{abstract}
From a psychosocial perspective, this text aims to discuss Education in times of a pandemic. It is based on the assumption that it is necessary to epistemologically elucidate a few theoretical notions that interweave relations of uncertainty and exclusion, present in daily practices, so that one can understand the effects of the pandemic in the educational scenario and reflect on action and overcoming strategies. It is based on Bourdieu (1997, 1998, 2002, 2015), Certeau (1998), Morin (2000, 2003), among others, to offer theoretical subsidies in order to reflect on the educational routine, its rules and strategies and exclusion processes. It is hoped, therefore, to identify the challenges posed by the uncertainties and the neoliberal scourge of these times of a pandemic, and to question the conditions of possibilities and forms of resistance, especially of the school, in guaranteeing social rights and a fairer and more inclusive education.
\end{abstract}

Keywords: Education. Relations of uncertainty and exclusion. Action and overcoming strategies.

Resumen: Desde una perspectiva psicosocial, el presente texto tiene como objetivo discutir la educación en tiempos de pandemia. Se parte del supuesto de la necesidad de dilucidar epistemológicamente algunas nociones teóricas, que entrelazan relaciones de incertidumbre y exclusión, presentes en las prácticas cotidianas, para poder

\footnotetext{
' Pós-Doutora em Psicologia da Educação, Pontifícia Universidade Católica de São Paulo (PUC/SP). Doutora em Educação pela Faculdade de Educação da USP (FEUSP). Professora do Programa de Pós-Graduação Stricto Sensu da Universidade Católica de Santos (UNISANTOS). Pesquisadora do Centro Internacional de Estudos em Representações Sociais e Subjetividade - Educação (CIERS-ed/FCC). E-mail: mfabdalla@uol.com.br.
}

Olhar de professor, Ponta Grossa, v. 24, p. I-10, e-15972.048, 2021.

Disponível em <https://revistas2.uepg.br/index.php/olhardeprofessor> 
Relações de incerteza e exclusão: é possível pensar em estratégias para a educação em tempos de pandemia?

comprender los efectos de la pandemia en el escenario educativo y reflexionar sobre las estrategias de acción y superación. Se ha fundamentado en Bourdieu (1997, 1998, 2002, 2015), Certeau (1998), Morin (2000, 2003), entre otros, para ofrecer bases teóricas en el sentido de reflexionar sobre las actividades educativas cotidianas, sus reglas y estrategias y sus procesos de exclusión. De este modo, se espera identificar los desafíos que plantean las incertidumbres y el flagelo neoliberal de esta época de pandemia, así como cuestionar las condiciones relativas a las posibilidades y formas de resistencia, sobre todo de la escuela, con el propósito de garantizar los derechos sociales y una educación más justa e inclusiva.

Palabras-clave: Educación. Relaciones de incertidumbre y exclusión. Estrategias de acción y superación.

\section{Introdução}

Não admira que, pelo vírus, se fale de guerra. [...] Mas uma guerra com um inimigo invisível que pode aninhar-se em qualquer outro homem é a mais absurda das guerras. É, na verdade, uma guerra civil. O inimigo não está fora, está dentro de nós (AGAMBEN, 2020, p. 19).

Nestes tempos atuais em que nos confrontamos com a pandemia, pensamos muito nas relações de incerteza e de exclusão frente a este "inimigo invisível" (AGAMBEN, 2020), que nos desequilibra, em especial, quando se quer tratar da Educação. Incerteza e exclusão, por conta da lógica neoliberal, que continua a alimentar (e com mais vigor) modelos de racionalidade técnica, referenciados na agenda empresarial com "pacotes" de receitas ou técnicas a serem aplicados, de forma incerta e ilusória, e que acabam por provocar tempos e espaços de exclusão. Trata-se de excluir, principalmente, os estudantes das escolas públicas, considerando que suas famílias mal têm seus direitos mínimos garantidos para uma sobrevivência digna, quanto mais o direito ao acesso à internet e a outros meios e/ou ferramentas tecnológicas. Além disso, dispositivos legais são impostos, como o Parecer CNE/CP n. 5/2020 (BRASIL, 2020), que normatiza a reorganização do Calendário Escolar, em razão da Pandemia da Covid-19, provocando também a ilusão de que o ano letivo escolar sobreviverá do mesmo jeito, apesar dos desafios postos por esses tempos.

Com base nessas colocações, este texto, fundamentado em Bourdieu (1997a, 1997b, 1997c, 1998a, 1998b, 2002, 2004, 2015), Certeau (1998), Morin (2000, 2003), entre outros, pretende refletir sobre duas questões: quais são os efeitos da pandemia para uma educação pública comprometida com a luta contra a desigualdade, injustiça e exclusão social? E se é possível pensar em estratégias de ação para que se possam superar os desafios desses tempos de pandemia? Tendo em vista essas questões, o texto objetiva discutir a Educação em tempos de pandemia, partindo do pressuposto de que é preciso elucidar epistemologicamente algumas noções teóricas, que entretecem as relações de incerteza e de exclusão presentes nas práticas cotidianas, para que se possa identificar os efeitos da pandemia no cenário educacional, e refletir sobre estratégias de ação e superação. Assumimos, assim, um "olhar psicossocial para a educação" (ABDALLA; VILLAS BÔAS, 2018, p. 38), no sentido de compreender 
"[...] ○ conjunto de significações sociais presentes no processo educativo, sem desconsiderar o sofrimento do sujeito frente aos problemas sociais".

\section{Das noções teóricas para entender os efeitos da pandemia}

Tomamos aqui algumas noções teóricas que nos ajudam a pensar sobre os efeitos da pandemia e encontrar formas possíveis de superação. Reconhecemos, de início, e junto com Santos (2020, p. 5), que estamos vivendo, nestes últimos tempos, "em permanente estado de crise"; e que esta crise não é passageira, e não irá ser resolvida tão cedo. Segundo Santos (2020, p. 6), ela tem dois objetivos: "legitimar a escandalosa concentração de riqueza e boicotar medidas eficazes para impedir a iminente catástrofe ecológica [...]”. Por isso, continua o autor, “[...] a pandemia vem apenas agravar uma situação de crise que a população mundial tem vindo a ser sujeita" (SANTOS, 2020, p. 6).

Além disso, há, nesta direção, um agravamento do sofrimento existencial, que nos faz refletir também sobre a crise de identidade. E, ao discutir sobre este tema, lembramo-nos de Hall (1999, p. 7), que considera que a crise de identidade ${ }^{2}$ faz parte "[...] de um processo mais amplo de mudança, que está deslocando as estruturas e processos centrais das sociedades modernas e abalando os quadros de referência que davam aos indivíduos uma ancoragem estável no mundo social”.

$\mathrm{Na}$ verdade, estamos, mesmo, sendo abalados em nossos quadros de referências. Há uma racionalidade liberal e excludente, permeada por pautas neoliberais, que se alargam dentro do campo da educação, em defesa da privatização, promovendo práticas conservadoras e autoritárias, que tendem a se instaurar, de forma acelerada, com os efeitos da pandemia. A par dessas questões, vivemos em um "tempo acidentado", conforme Certeau (1998), que, certamente, não é o “tempo programado”, e, sim, o tempo do "imprevisto", pois se trata de um "[...] tempo que passa, separa ou liga (e que sem dúvida jamais foi pensado)" (CERTEAU, 1998, p. 31I). Tempo este em que as vidas, em especial, dos estudantes das escolas públicas se encontram ainda mais ameaçadas; pois, como denuncia Arroyo (2019, p. II): “[...] nas escolas públicas não há como ignorar os corpos precarizados que chegam marcados pela fome, pelos sofrimentos, pelas múltiplas violências e doenças”. Esses estudantes vivem, ou melhor, sobrevivem amontoados, vitimizados e ameaçados por este cenário de crise, que já envolve um número lastimável de contaminados e de mortes. Há, ainda, um agravamento maior dessa situação

\footnotetext{
${ }^{2}$ Para Hall (1999), identidade é um conceito "demasiadamente complexo" (p. 8), devido às mudanças estruturais das sociedades modernas, que estão "[...] fragmentando as paisagens culturais de classe, gênero, sexualidade, etnia, raça e nacionalidade, que, no passado, nos tinham fornecido sólidas localizações como indivíduos sociais" (HALL, 1999, p. 9). Segundo o autor, "estas transformações sociais estão também mudando nossas identidades pessoais, abalando a ideia que temos de nós próprios como sujeitos integrados" (HALL, 1999, p. 9). O que nos leva a pensar, junto com ele, em "crise de identidade", que é muito mais aguçada nestes tempos de pandemia.
}

Olhar de professor, Ponta Grossa, v. 24, p. I-10, e-I5972.048, 202 I.

Disponível em <https://revistas2.uepg.br/index.php/olhardeprofessor> 
Relações de incerteza e exclusão: é possível pensar em estratégias para a educação em tempos de pandemia? por conta da política do governo atual, pelo colapso da saúde e pela pauperização das condições humanas.

Esbarramos, também, nestes tempos, como diria Bourdieu (1997a, p. 226), com dois obstáculos: "a resignação de indivíduos desmobilizados e desmoralizados por uma longa série de fracassos e decepções; e a inércia de uma administração atomizada e atomizante, configurada na rigidez de suas rotinas e pressupostos [...]", gerando, uma "violência branda e invisível" a depender do estado de relações de força (BOURDIEU, 2002). É, assim, que nos sentimos, pendurados por um fio de vida, que nos assusta; pois, de um lado, somos vítimas da Covid-19, porque os governos deixaram de investir na ciência, o que aprofunda as nossas incertezas sobre o que virá; e, de outro, somos puxados para uma crise, ainda maior, devido aos problemas políticos, econômicos e sociais, que nos deixam indignados e angustiados.

Há que se assumir, então, como Bourdieu (1997b, p. 694) nos ensina, uma postura de “[...] reflexividade, que é sinônimo de método, mas uma reflexividade reflexa, baseada num 'trabalho', num 'olho' sociológico" (grifos do autor). Postura esta que nos faça compreender a realidade atual, seus efeitos no campo da educação, onde atuamos; em especial, para que encontremos saídas de superação.

Neste sentido se quisermos desvendar os efeitos da pandemia na Educação, consideramos necessário pensar em algumas noções teóricas. A primeira delas é a noção de poder simbólico, entendido como "[...] poder invisível o qual só pode ser exercido com a cumplicidade daqueles que não querem saber que lhe estão sujeitos ou mesmo que o exercem" (BOURDIEU, 1998a, p. 7-8). Para a teoria bourdieusiana, o poder simbólico produz efeitos desencadeadores, denominados como relações de força e de sentido, que culminam em atos de submissão e de obediência, e que são recheados, por um lado, de uma boa dose de crença; e, por outro, de violência simbólica ou formas de resistêncialexclusão. Além disso, o autor também considera que estes "[...] atos de submissão e de obediência são atos cognitivos, que, como tais, ativam estruturas cognitivas, categorias de percepção, esquemas de percepção, princípios de visão e divisão, todo um conjunto de coisas [...]" (tradução livre) (BOURDIEU, 2015, p. 229).

Dentre essas formas simbólicas, que são, segundo Bourdieu (2015, p. 230), "princípios de construção da realidade social”, destacamos as noções de regra e de estratégia. Regra, para Bourdieu (2004), pode ser traduzida como princípio de tipo jurídico, que é conhecido e dominado pelos agentes e/ou como um conjunto de regularidades objetivas, que se impõem àqueles que entram em um jogo. Enquanto que estratégia (BOURDIEU, 2004, p. 79) significa: "[...] o senso prático, ou, se preferirmos, o que os esportistas chamam de sentido do jogo, como domínio prático da lógica ou da necessidade imanente de um jogo, que se adquire pela experiência de jogo e que funciona aquém da consciência e dos discursos" (grifos do autor). O que implica compreender que a ideia de estratégia está 
fundamentada na ação social e no conceito de habitus, que dispõe a relação dos agentes no mundo social, oferecendo-lhes um sentido do jogo, ou seja, um sentido prático, para além das regras do jogo. Bourdieu (2002) entende, também, a estratégia como uma ação prática inspirada pelos estímulos de determinada situação histórica, e que envolve, ainda, um "[...] apostar (no sentido de empenhar-se) [...]" (BOURDIEU, 2002, p. 196); ao mesmo tempo, que “[...] visa limitar a insegurança que é correlativa da imprevisibilidade" (BOURDIEU, 2002, p. 197).

Nesta mesma linha, Certeau (1998) nos esclarece sobre o significado de estratégia, que é "o lugar do poder e do querer próprios” (CERTEAU, 1998, p. 99). Para ele, o “querer próprio" significa uma condição de poder em ação, que é a condição do sujeito e não o efeito do poder sobre ele. E Morin (2003) considera a estratégia como uma via que "procura incessantemente reunir as informações colhidas e os acasos encontrados durante o percurso" (MORIN, 2003, p. 62). Essas concepções sobre a noção de estratégia nos levam a pensar a respeito da necessidade em defini-la, especialmente, para refletir sobre o processo educativo e as condições de autonomia dos sujeitos por ele envolvidos na busca de possibilidades de aprendizagem frente às múltiplas e incertas situações criadas por esta pandemia.

Diante das noções até aqui enredadas, é preciso compreender, mais a fundo, a noção de exclusão social, especialmente, quando tratamos de estabelecer relações com as incertezas dos tempos atuais. Tomamos, assim, a concepção de Sawaia (2012), que destaca que há dimensões da exclusão, que precisam ser compreendidas, e ressalta: "[...] a dimensão objetiva da desigualdade social, a dimensão ética da injustiça e a dimensão subjetiva do sofrimento" (SAWAIA, 20I2, p. 8). Não cabe aqui definir cada uma das dimensões; entretanto, é preciso destacar que elas alimentam a vontade de problematizar: os efeitos dessa "guerra civil" (AGAMBEN, 2020), vivenciada por todo o planeta; o problema da mudança de um novo tempo, cujas expectativas se reduzem à própria sobrevivência; e as condições de possibilidades e formas de resistência para superar os desafios que estão postos por esta nova realidade. E, neste cenário, resta-nos perguntar: é possível pensar em estratégias de ação e de superação?

\section{Reflexões finais}

O pensamento deve, então, armar-se e aguerrir-se para enfrentar a incerteza. Tudo que comporta oportunidade comporta risco, e o pensamento deve reconhecer as oportunidades de risco como os riscos das oportunidades (MORIN, 2000, p. 91).

Ao desenvolver algumas das noções que, para nós, desvelam a prática do cotidiano, reconhecendo, também, as palavras anteriores de Morin (2000), passamos a explicitar, pelo menos, dois efeitos da pandemia na Educação, com a pretensão de compreender as relações 
Relações de incerteza e exclusão: é possível pensar em estratégias para a educação em tempos de pandemia?

de incerteza e de exclusão e indicar estratégias de ação e superação.

O primeiro efeito da Covid-19 na Educação tem a ver com a compreensão do significado da incerteza. Se este tempo de pandemia não é percebido de imediato, porque é um "tempo acidentado", como nos ensina Certeau (1998), como conceber a incerteza de forma pedagógica? Encontramos três "saídas" ou estratégias de ação, que entendemos como condições de possibilidade e formas de resistência, na garantia dos direitos sociais e de uma educação mais justa e inclusiva conforme esclarecemos adiante.

A primeira tem a ver em assumir um "olhar psicossocial para a educação" (ABDALLA; VILLAS BÔAS, 20I8), ou seja, uma "postura epistemológica”, ao reinterpretar as novas concepções, tanto sociais, políticas, econômicas, de saúde e educacionais, que possam fazer com que alunos e professores reaprendam a compreender a realidade da forma como ela está sendo constituída. Nesta direção, é preciso que se garanta, ainda mais neste tempo de pandemia, o acesso e a permanência daqueles alunos da educação básica, que se encontram em situações mais fragilizadas e fora dos espaços de aprendizagem, porque, agora, também estão excluídos digitalmente. O que implica a necessidade de políticas de afirmação e de inclusão social, assim como investimentos públicos, que ofereçam condições de possibilidade para que se construa uma sociedade mais plural, mais democrática e, sobretudo, mais justa.

A segunda está relacionada ao papel decisivo da noção de incerteza para o processo de pensar no campo da educação. Pois, a compreensão da realidade de hoje exige que se transcenda às aprendizagens rotineiras, cujo ensino, muitas vezes, só está preocupado, neste momento, em cumprir a carga horária nas plataformas digitais e transmitir conteúdos, que nem sempre são significativos e contextualizados com a realidade dos alunos. Para isso, há necessidade de se pensar em outros modos de formação e de atuação docente, que possam promover estratégias de ação e de superação no enfrentamento dos desafios e das incertezas daí decorrentes, a fim de contribuir para um processo educacional mais contextualizado e significativo para toda comunidade escolar.

A terceira poderia se direcionar para repensar a visão que temos da própria gestão educacional, cuja ordem está representada pela legislação e pela organização, por meio de normas legais, que estruturam os espaços e tempos escolares. Considerar, neste tempo de incertezas, que se tem uma outra organização e/ou dinamicidade para a realidade escolar. $E$ que é preciso que o coletivo da Escola mantenha a sua autonomia como sujeitos criativos, em 
permanente renovação, e não como reféns de regras impostas. É importante, então, que se abram espaços possíveis para um trabalho em rede, que seja efetivo, afetivo e significativo, para todos envolvidos.

O segundo efeito se relaciona com o entendimento da exclusão social nestes tempos de pandemia. É preciso discutir, no campo educacional, os problemas de toda ordem que ameaçam as vidas, em especial, de estudantes, que sofrem violências físicas e/ou simbólicas. $E$, dessa forma, indicar as estratégias de ação/superação necessárias, quando se quer abordar o tema da exclusão social sob a perspectiva da desigualdade social, da ética da injustiça e do sofrimento (SAWAIA, 20I2).

Ao tratar da perspectiva da desigualdade social, é preciso, primeiro, refletir, de acordo com Santos (2006, p. 285), sobre a função do Estado capitalista moderno, que é: “[...] manter a desigualdade dentro dos limites que não viabilizem a integração subordinada, designada de inclusão social pelas políticas estatais" (grifos nossos). E que esta integração se dá pelo trabalho e pelo consumo: os "dois lados da inclusão subordinada" (SANTOS, 2006, p. 286). Sugerimos, então, estratégias de ação/superação que discutam a desigualdade como "inclusão subordinada", e desconstruam os injustos contravalores estruturantes das desigualdades de classe, raça, etnia e gênero (ARROYO, 2019), para legitimar as lutas por justiça reivindicada pelos movimentos sociais.

Quanto à dimensão ética da injustiça social, será necessário debater questões sobre a convivência ética escolar, conforme assinalam Tognetta, Vinha e Avilés Marinez (2014), para que os vínculos afetivos, sociais e éticos sejam reforçados e o conhecimento construído possa ser contextualizado e significativo. É urgente, como diria Bourdieu (1998b, p. 19), "criar condições para um trabalho coletivo", e que seja possível "[...] mobilizar as vontades, sem mistificar as consciências". O que implica introduzir estratégias de ação que façam com que os sujeitos envolvidos pensem em escolhas e decisões éticas, transformando-as em atos de resistência contra a desigualdade, injustiça e exclusão sociais.

Em relação ao sofrimento humano, é preciso entendê-lo como a dimensão subjetiva da exclusão social (SAWAIA, 20I2) e como um dos efeitos da violência física ou simbólica, porque fundado em uma relação de força (BOURDIEU, 20I5). Sem entrar em uma análise mais densa, a pandemia provocou mudanças, como diria Bourdieu (2002, p. 162), "na própria estrutura do campo", ou seja, "nas leis que organizam a acumulação do capital simbólico e sua circulação”, 
Relações de incerteza e exclusão: é possível pensar em estratégias para a educação em tempos de pandemia?

assim como no habitus, entendido como "[...] essa espécie de senso prático do que se deve fazer em dada situação" (BOURDIEU, 1997c, p. 42). Frente a essas mudanças, intensificou-se a sensação de insegurança e de incerteza, aprofundando o sofrimento daqueles que vivem, no cenário social e educacional brasileiro, e se sentem angustiados frente ao desemprego, às condições precárias, que se intensificam, e ao medo de não conseguirem sobreviver à COVID19. E, nesta perspectiva, é preciso que o coletivo escolar explicite as formas sutis da exploração humana, da degradação do trabalho, das condições de vida cada vez mais precarizadas, e favoreça momentos de trocas de experiências e de diálogos, que sejam mais reflexivos e inclusivos.

Todavia, o que vemos, hoje, na contramão das estratégias que propomos, são grupos empresariais, de um lado, e militares, de outro, controlando a educação das camadas populares e colocando os artefatos tecnológicos para impulsionar um verdadeiro sistema de exclusão (SANTOS, 2006). O que nos leva a pensar que estamos diante de um momento extraordinário de sofrimento humano movido por problemas de toda ordem (político, econômico, sanitário e educacional), agravado pela crença na utopia neoliberal e que reforça espaços e tempos de injustiça e exclusão social.

Mais do que nunca, é necessário que interroguemos as condições de possibilidades e também as formas de resistência para enfrentar esses desafios, desenvolvendo estratégias de ação/superação na direção da garantia dos direitos sociais e de uma educação mais justa e inclusiva. Que possamos, assim, reconhecer, como anuncia Morin (2000, p. 91), "as oportunidades de risco como os riscos das oportunidades!" E, neste sentido, (re) inventar formas de pensar e de agir a fim de continuar na luta por uma Educação que seja comprometida com a cidadania, a democracia e a justiça social.

\section{Referências}

ABDALLA, M. F. B.; VILLAS BÔAS, L. Um olhar psicossocial para a educação. Cadernos de Pesquisa, São Paulo, v. 48, n. 167, p. I4-4I, jan./mar. 2018 . Disponível em: <https://doi.org//0.1590//98053|44277>.

AGAMBEN, G. Reflexões sobre a peste: ensaios em tempos de pandemia. Tradução de Isabella Marcatti. São Paulo: Boitempo, 2020.

ARROYO, M. G. Vidas ameaçadas: exigências-respostas éticas da educação e da docência. Petrópolis: Vozes, 2019. 
BOURDIEU, P. Uma missão impossível. In: BOURDIEU, P. (Coord.). A miséria do mundo. Petrópolis: Vozes, 1997a.

BOURDIEU, P. Compreender. In: BOURDIEU, P. (Coord.). A miséria do mundo. Petrópolis: Vozes, I997b.

BOURDIEU, P. Razões práticas: sobre a teoria da ação. Tradução de Mariza Corrêa. Campinas: Papirus Editora, 1997c.

BOURDIEU, P. O poder simbólico. 2. ed. Tradução de Fernando Tomaz. Rio de Janeiro: Bertrand Brasil, 1998a.

BOURDIEU, P. Contrafogos: táticas para enfrentar a invasão neoliberal. Tradução de Lucy Magalhães. Rio de Janeiro: Jorge Zahar, 1998b.

BOURDIEU, P. A produção da crença: contribuição para uma economia dos bens simbólicos. Tradução de Guilherme João de Freitas Teixeira. São Paulo: Zouk, 2002.

BOURDIEU, P. Coisas ditas. Tradução de Cássia R. da Silveira e Denise M. Pegorim. São Paulo: Brasiliense, 2004.

BOURDIEU, P. Sobre el Estado: cursos en el Collège de France (1989-1992). Edición de Patrick Champagne, Remi Lenoir, Franck Poupeau y Marie-Christine Rivière. Traducción de Pilar Gonzàlez Rodríguez. Barcelona: Editorial Anagrama, 2015.

BRASIL. Ministério da Educação. Conselho Nacional de Educação. Parecer 5/2020. Reorganização do Calendário Escolar e da possibilidade de cômputo de atividades não presenciais para fins de cumprimento da carga horária mínima anual, em razão da pandemia COVID-19. Brasília: MEC, 2020.

CERTEAU, M. A invenção do cotidiano: artes de fazer. 3. ed. Tradução de Ephraim Ferreira Alves. Petrópolis: Vozes, 1998.

HALL, S. A identidade cultural na pós-modernidade. 3. ed. Tradução de Tomaz Tadeu da Silva e Guacira Lopes Louro. Rio de Janeiro: DP\&A, 1999.

MORIN, E. Os sete saberes necessário à educação do futuro. São Paulo: Cortez; Brasília: Unesco, 2000.

MORIN, E. A cabeça bem-feita: repensar a reforma, reformar o pensamento. 8. ed. Rio de Janeiro: Bertrand Brasil, 2003.

SANTOS, B. S. A gramática do tempo: para uma nova cultura política. São Paulo: Cortez, 2006.

SANTOS, B. S. A cruel pedagogia do vírus. Coimbra: Edições Almedina, 2020.

SAWAIA, B. (Org.). As artimanhas da exclusão: análise psicossocial e ética da desigualdade social. 12. ed. Petrópolis: Vozes, 2012.

TOGNETTA, L. R. P.; VINHA, T. P.; AVILÉS MARTINÉZ, J. M. Bulling e a negação da convivência ética: quando a violência é um valor. International Journal of Developmental and Educational Psychology, INFAD Revista de Psicología, Badajoz, v. 7, n. I, p. 315-322, 2014. Disponível em: <https://doi.org//0.17060/ijodaep.20I4.nI.v7.802>. 
Recebido em: I 3 de junho de 2020.

Versão corrigida recebida em: 27 de agosto de 2020.

Aceito em: 29 de outubro de 2020.

Publicado online em: 28 de maio de 2021 .

(a) $\underset{10}{-18}$ 